Jurusan Ilmu Kesejahteraan Sosial Fakultas Ilmu Sosial dan Ilmu Politik Universitas Halu Oleo

\title{
UPAYA PERLINDUNGAN MASALAH KESEJAHTERAAN SOSIAL ANAK DARI KELUARGA PEMULUNG (Studi di Tempat Pembuangan Akhir TPA Puuwatu Kelurahan Puuwatu Kecamatan Puuwatu Kota
}

Suci Dwi Rahmayuni, Suharty Roslan, Tanzil

Program Studi Ilmu Kesejahteraan Sosial, Program Studi Sosiologi, FISIP, Universitas Halu Oleo

Email: sucidwirahmayuni@gmail.com, Suhartyroslan1967@gmail.com, tanzilsosio@gmail.com

\begin{abstract}
ABSTRAK
Penelitian ini bertujuan untuk (1) Untuk mengetahui masalah kesejahteraan sosial yang dihadapi anak pemulung di daerah pemukiman Tempat Pembuangan Akhir TPA Puuwatu Kelurahan Puuwatu Kecamatan Puuwatu Kota Kendari(2) Untuk mengetahui upaya pelindungan yang dilakukan dari berbagai pihak untuk mengatasi masalah kesejahteraan sosial yang dihadapi anak pemulung di daerah pemukiman Tempat Pembuangan Akhi TPA Puuwatu Kelurahan Puuwatu Kecamatan Puuwatu Kota Kendari. Penelitian ini di lakukan di Tempat Pembuangan Akhir TPA Puuwatu Kelurahan Puuwatu Kecamatan Puuwatu Kota Kendari. Analisi data yang di gunakan adalah analisis kualitatif sedangkan sumber data menggunakan data primer dan skunder. Teknik pengumpulan data ini menggunakan observasi, wawancara, dan dokumentasi. Hasil penelitian yang di lakukan bahwa, Masalah Kesejahteraan Sosial yang dihadapi anak pemulung di daerah pemukiman Tempat Pembuangan Akhir TPA Puuwatu Kelurahan Puuwatu Kecamatan Puuwatu Kota Kendari yaitu terdiri dari Masalah Sosial, Masalah Ekonomin, Masalah Pendidikan dan Masalah Kesehatan, selanjutnya Upaya pelindungan yang dilakukan dari berbagai pihak untuk mengatasi masalah kesejahteraan sosial yang dihadapi anak pemulung di daerah pemukiman TPA PuuwatuKelurahan Puuwatu Kecamatan Puuwatu Kota Kendari yaitu perlindungan yang di lakukan dari pihak Masyarakat, pihak Pemerintah dan pihak Swasta.
\end{abstract}

Kata Kunci: Upaya Perlindungan, Masalah Kesejahteraan Sosial Anak, Keluarga Pemulung

\section{PENDAHULUAN}

Kesejahteraan anak merupakan hak setiap anak, ketika kesejahteraan anak terpenuhi anak akan berkembang secara optimal sehingga lahir generasi yang berkualitas. Setiap anak lahir dengan hak yang sama untuk dimulai dengan hidup yang sehat, pendidikan dan rasa aman, masa kanak-kanak merupakan kesempatan utama yang akan membawa kepada masa dewasa yang produktif dan penuh kepastian. (unicef: 2016). 


\section{WELVAART}

\section{JURNAL ILMU KESEJAHTERAAN SOSIAL}

Jurusan Ilmu Kesejahteraan Sosial Fakultas Ilmu Sosial dan Ilmu Politik Universitas Halu Oleo

Dalam pemenuhan kesejahteraan anak seringkali berkaitan dengan kemiskinan. Masih banyak anak-anak belum mendapat hak dan tidak memiliki sesuatu yang dibutuhkan untuk tumbuh sehat dan kuat. Hal ini disebabkan karena tempat mereka lahir, ras, etnik atau gender atau hidup dalam kemiskinan atau ketidakberuntungan.

Twikromo (1999: 67) menjelaskan bahwa kondisi sosial ekonomi masyarakat pemulung sangat rendah dan memprihatinkan. Hal ini terlihat dengan adanya ketidakberdayaan pemulung menghadapi tantangan kemajuan di kota. Walaupun demikian para pemulung tetap hidup dan bertahan di kota karna tidak tersedianya lahan pertanian di pedesaan untuk mengolah lahan pertanian. Dengan demikian sebenarnya kemiskinan yang dialami olen pemulung adalah kompleks yakni selain tidak memiliki pendapatan dan pekerjaan yang jelas pemulung juga tidak memiliki lahan pertanian sebagai alternafit lainnya.

Suharto (2004 : 61) pemulung merupakan pekerjaan yang tidak diinginkan oleh mereka yang menjalankannya namun memulung merupakan salah satu cara bagi mereka agar dapat bertahan hidup dan memenuhi kebutuhan mereka. Sebagai masyarakat beranggapan negatif tentang pemulung, bahkan tidak jarang mereka menjauhi pemulung dan tidak ingin berkomunikasi dengan pemulung yang identik dengan sampah dan kondisi fisik maupun penampilan yang kumuh. Teori mengenai pemulung digunakan dalam penelitian ini untuk memberikan gambaran umum mengenai kategori pemulung dan kondisi pemulung dalam kehidupan masyarakat.

Beberapa ciri pemulung yang telah disebut diatas maka peneliti menyimpulkan pemulung adalah manusia yang pekerjaannya memungut sampah khususnya sampah yang memiliki nilai ekonomi. Sedangkan memulung adalah tindakan yang dilakukan oleh pemulung dalam aktivitas mengumpulkan sampah, memilah sampah, hingga proses menjual sampah kepada pengumpul. Kurang lebih aktivitas usaha memulung seperti itu tiap harinya dan berlangsung secara berulang-ulang. Dalam penelitian ini pemulung TPA Puuwatu biasanya mereka yang tiap hari memungut barang bekas, mengumpulkan dan memilah barang bekas di TPA tersebut dari pagi hingga sore hari. Pemulung tinggal di Kelurahan 


\section{WELVAART}

\section{JURNAL ILMU KESEJAHTERAAN SOSIAL}

Jurusan Ilmu Kesejahteraan Sosial Fakultas Ilmu Sosial dan Ilmu Politik Universitas Halu Oleo

yang berbatasan langsung dengan TPA Puuwatu yaitu Kelurahan Puuwatu. Pemulung di TPA Puuwatu termasuk kategori pemulung menetap, mereka tinggal di suatu Kelurahan dan bermata pencaharian sebagai pemulung.

Kondisi umum saat ini anak-anak dari keluarga pemulung di area pemukiman Tempat Pembuangan Akhir TPA Puuwatu Kota Kendari, dilihat dari segi sosial bahwa anak pemulung yang tinggal di daerah TPA Puuwatu mereka terkadang mengalami perkelahian walaupun hanya Masalah yang biasa-biasa saja. Dan dari segi ekonomi bahwa anak pemulung yang tinggal di TPA Puuwatu tidak menghasilkan uang karena hanya orang tua mereka yang melakukan kegiatan memulung dan menghasilkan uang tetapi ada juga beberapa anak pemulung yang sudah berusian 15 tahun ke atas sudah bisa menghasikan uang karena terkadang mereka ikut membantu kedua orang tuanya memulung di Tempat Pembuangan Akhir TPA. Dan dari segi pendidikan bahwa rata-rata anak pemulung yang tinggaldi daerah TPA Puuwatu kebanyakan yang bersekolah danyang tidak bersekolah hanya sedikit dan yang membuat mereka tidak bersekolah disebabkan faktor ekonomi dan malas. Dan yang terakhir darisegi kesehatan, bahwa anak pemulung yang tinggal di TPA Puuwatu jenis penyakit yang mereka alami seperti sakit pada umumnya yaitu diare, demam, gejala DBD dan flu, mereka terkena penyakit ini di karena kondisi lingkungan dan udara mereka yang kotor karena sampah dan juga mereka yang hidup berdampingan dengan sampah akan tetapi kebanyakan dari mereka kebal dengan penyakit seperti itu di karenakan kebiasaan dan pola hidup mereka yang setiap harinya hidup berdampingan dengan sampah. Adapun jumlah Kepala Keluarga di area pemukiman Tempat Pembuangan Akhir TPA Puuwatu yaitu sekitar 70 an KK, dimana masing-masing Kepala Keluarga tersebut tidak semuanya memiliki anak, jadi hanya terdapat 30 an anak pemulung dari $70 \mathrm{KK}$ tersebut. Berdasarkan uraian di atas penulis meneliti di daerah pemukiman Tempat Pembuangan Akhir (TPA) Puuwatu Kota Kendari. 


\section{WELVAART}

JURNAL ILMU KESEJAHTERAAN SOSIAL

Jurusan Ilmu Kesejahteraan Sosial

PEMBAHASAN

\section{Kondisi Geografis}

Kelurahan Puuwatu merupakan salah satu kelurahan yang ada di Wilayah Kecamatan Puuwatu dengan jarak dari pusat pemerintahan Kota Kendari kurang lebih 10 kilometer. Letak dari permukaan laut setinggi kurang lebih 200 M2 dengan keseluruhan luas wilaya kurang lebih 2.165 Ha. Dengan jumlah RW : 9 dan RT : 27

\section{Gambaran Singkat Kehidupan Pemulung di Area Pemukiman TPA}

Gambaran singkat kehidupan pemulung di sekitar Tempat Pembuangan Akhir TPA di Kelurahan Puuwatu sangat tergatung oleh kondisi lingkungan mereka, artinya mereka melakukan pekerjaan memulung karena pengaruh tempat tinggal mereka yang berdekatan dengan Tempat Pembuangan Akhir TPA Kota Kendari, dimana pemetintah Kota Kendari telah menjadikan tempat ini sebagai Tempat Pembuangan Sampah TPA sehingga menimbulkan minat dan motivasi masyarakat untuk berprofesi sebagai pekerja pemulung yang sifatya tetap di tempat ini. Kemudian bahwa masyarakat khususnya di sekitar Tempat Pembuangan Akhir TPA ini adalah masyarakat pinggiran Kota yang kurang memiliki pendidikan memadai sehingga peluang untuk mendapatkan pekerjaan yang lebih layak, sangat, rendah dan terbatas. Dimana pekerjaan memulung ini tidak membutuhkan modal yang besar dan skil yang tinggi tetapi hanya mengandalkan tenaga saja dengan menggunakan peralatan gancong dan karung. Hal ini membuat masyarakat yang bermukim di sekitar lingkungan ini melakukan pekerjaan sebagai pemulung untuk memenuhi kebutuhan pokok sehari-hari.

Masalah Kesejahteraan Sosial yang di Hadapi Anak Pemulung di Area Pemukiman Tempat Pembuangan Akhir TPA

1. Masalah Sosial

Masalah sosial merupakan perbedaan antara harapan dan kenyataan atau sebagai kesenjangan antara situasi yang ada dengan situasi yang seharusnnya. Masalah sosial dipandang oleh sejumlah orang dalam masyarakat sebagai sesuatu kondisi yang tidak diharapkan, sama halnya di area pemukiman Tempat Pembuangan Akhir TPA Puuwatu salah satu malasah yang sering terjadi yaitu 


\section{WELVAART}

\section{JURNAL ILMU KESEJAHTERAAN SOSIAL}

Jurusan Ilmu Kesejahteraan Sosial Fakultas Ilmu Sosial dan Ilmu Politik Universitas Halu Oleo

cekcok seperti perkelahian atau pertengkaran antara anak-anak pemulung dan perbedaan pendapat antar tetangga yang tinggal di daerah tersebut.

2. Masalah Ekonomi

Masalah ekonomi adalah suatu masalah yang terjadi karena terbatasnya jumlah sumber daya dibandingkan dengan adanya kebutuhan manusia setiap harinya yang semakin meningkat.

3. Masalah Pendidikan

Permasalahan pendidikan adalah segalah sesuatu hal yang merupakan masalah dalam pelaksanaan kegiatan pendidikan. Seperti yang terdapat di area pemukiman Tempat Pembuangan Akhir TPA Puuwatu, pendidikan di Kelurahan Puuwatu tersebut sudah cukup mendukung akan tetapi anak-anak yang tinggal di area pemukiman Tempat Pembuangan Akhir TPA Puuwatu mereka terhalang oleh biaya pendidikan yang tiap tahun meningkat karena hanya mengharapkan pendapatan dari hasil memulung.

4. Masalah Kesehatan

Kesehatan merupakan keadaan sejahtera dari badan, jiwa dan solusi yang memungkinkan setiap orang hidup produktif secara sosial dan ekonomis, masalah kesehatan ialah masalah kompleks yang merupakan hasil dari berbagai masalah lingkungan yang bersifat alamiah maupun buatan manusia.

\section{Upaya Perlindungan yang di Lakukan dari berbagai pihak untuk Mengatasi}

Masalah Kesejahteraan Sosial yang di Hadapi Anak Pemulung di Area Pumukiman TPA

a. Masyarakat

Masyarakat merupakan orang-orang yang hidup bersama dan berdampingan seperti yang terdapat di area pemukiman Tempat Pembuangan Akhir TPA Puuwatu dan mereka terdiri dari berbagai jenis manusia yang berbeda, yang memiliki fungsi berbeda, yang terbentuk dan dilihat hanya dari segi fungsi bukan dari rasa suku maupun cinta dan sejenisnya. Seperti halnya di area pemukiman Tempat Pembuangan Akhir TPA Puuwatu dari pihat masyarakat yang menjadi salah satu pihak yang berusaha untuk melakukan upaya perlindungan untuk mengatasi permasalahan sosial anak dibidang ekonomi dan pendidikan 
melalui mahasiswa dan masyarakat yang biasanya turun langsung mengajar anakanak dan memberikan bantuan-bantuan seperti makanan, sembako dan pakaian layak pakai, seperti dari ibu-ibu majelis talim, beberapa orang yang mengadakan syukuran atas bertambah usuainya dan membagi-bagi makanan di TPA dan dari pihak masyarakat lainnya

b. Pemerintah

Pihak pemerintah adalah organisasi yang memiliki kewenangan untuk membuat dan menerapkan hukum serta undang-undang di wilayah tertentu, yang juga berusaha untuk melakukan upaya perlindungan untuk mengatasi permasalahan sosial anak pemulung di area pemukiman Tempat Pembuangan akhir TPA Puuwatu dibidang pendidikan, ekonomi dan kesehatan melalui pihak sekolah dan posyandu terkadang juga mereka di memberikan sembako.Seperti halnya di area pemukiman Tempat Pembuangan Akhir TPA Puuwatu dari pihak pemerintah yang membantu mensejahterakan anak pemulung di TPA itu terdiri dari.

\section{c. Pihak Swasta}

Pihak swasta juga berusaha untuk melakukan upaya perlindungan untuk mengatasi permasalahan sosial anak anak dibidang ekonomi seperti memberikan bantuan-bantuan berupa sembako dan pakaian layak pakai dan pihak swasta yang datang terdiri dari pihat perusahaan-perusahaan seperti perusahaan culombus, pembiayaan, showroom motor/mobil, dan pegawai-pegawai perbankan lainnya.

\section{Kesejahteraan Anak}

Kesejahteraan anak merupakan suatu tata kehidupan dan penghidupan anak yang dapat menjamin pertumbuhan dan perkembangannya dengan wajar, baik secara rohani, jasmani, maupun sosial. Berdasarkan hasil wawancara diatas mengenai upaya perlindungan yang di lakukan untuk mengatasi masalah kesejahteraan sosial yang di hadapi anak pemulung di area pumukiman TPA Puuwatu Kota Kendari yang diantaranya dilakukan oleh pihak masyarakat, pemerintah, dan swasta maka hal tersebut akan berdampak secara langsung pada terpenuhinya kesejahteraan anak di bidang ekonomi, pendidikan, dan kesehatan. Masyarakat merupakan sekelompok manusia yang terjalin erat karena sistem 


\section{WELVAART}

\section{JURNAL ILMU KESEJAHTERAAN SOSIAL}

Jurusan Ilmu Kesejahteraan Sosial Fakultas Ilmu Sosial dan Ilmu Politik Universitas Halu Oleo

tertentu, tradisi tertentu dan hukum tertentu yang sama, serta mengarah pada kehidupan kolektif dan masyarakat inilah yang menjadi salah satu pihak yang berusaha memenuhi kesejahteraan anak dibidang ekonomi dan pendidikan melalui mahasiswa dan masyarakat yang biasanya turun langsung mengajar anak-anak dan memberikan bantuan-bantuan seperti makanan, sembako dan pakaian layak pakai. Selanjutnya pihak pemerintah adalah organisasi yang memiliki kewenangan untuk membuat dan menerapkan hukum serta undang-undang di wilayah tertentu, yang juga berusaha untuk melakukan pemenuhan kesejahteraan sosial anak dibidang pendidikan, ekonomi dan kesehatan melalui pihak sekolah dan posyandu terkadang juga mereka di berikan sembako. Selanjutnya pihak swasta juga berusaha untuk membantu pemenuhan kesejahteraan sosial anak dibidang ekonomi seperti memberikan bantuan-bantuan berupa sembako dan pakaian layak pakai.

\section{PENUTUP}

Penelitian ini dilaksanakan untuk mengetahui masalah kesejahteraan sosial yang dihadapi anak pemulung di area pemukiman TPA Puuwatu Kota Kendari dan upaya perlindungan masalah kesejahteraan anak di TPA Puuwatu Kota Kendari. Berdasarkan data yang terkumpul dan setelah dilakukan penelitian, maka dapat diambil kesimpulan bahwa.

1. Masalah kesejahteraan sosial anak yang dihadapi anak pemulung di dipemukiman Tempat Pembuangan Akhir TPA Puuwatu Kota Kendari yaitu masalah sosial, ekonomi, pendidikan dan kesehatan.Masalah sosial dipandang oleh sejumlah orang dalam masyarakat sebagai sesuatu kondisi yang tidak diharapkan, sama halnya di area pemukiman Tempat Pembuangan Akhir TPA Puuwatu salah satu malasah yang biasa terjadi hanyalah perbedaan pendapat antar tetangga yang tinggal di daerah tersebut. Masalah Ekonomi adalah suatu masalah yang terjadi karena terbatasnya jumlah sumber daya dibandingkan dengan adanya kebutuhan manusia setiap harinya yang semakin meningkat. Masalahan Pendidikan adalah segalah sesuatu hal yang merupakan masalah dalam pelaksanaan kegiatan pendidikan. Seperti yang terdapat di area pemukiman Tempat 


\section{WELVAART}

JURNAL ILMU KESEJAHTERAAN SOSIAL

Jurusan Ilmu Kesejahteraan Sosial Fakultas Ilmu Sosial dan Ilmu Politik

Pembuangan Akhir TPA Puuwatu, pendidikan ditempat tersebut sudah cukup mendukung akan tetapi mereka terhalang oleh biaya pendidikan yang tiap tahun meningkat. Masalah Kesehatan merupakan keadaan sejahtera dari badan, jiwa dan solusi yang memungkinkan setiap orang hidup produktif secara sosial dan ekonomis, masalah kesehatan ialah masalah kompleks yang merupakan hasil dari berbagai masalah lingkungan yang bersifat alamiah maupun buatan manusia.

2. Upaya Perlindungan yang di Lakukan untuk Mengatasi Masalah Kesejahteraan Sosial yang di Hadapi Anak Pemulung di Area Pumukiman TPA dilakukan oleh beberapa elemen diantara adalah Masyarakat, Pemerintah dan Swasta. Masyarakat merupakan sekelompok manusia yang terjalin erat karena sistem tertentu, tradisi tertentu dan hukum tertentu yang sama, serta mengarah pada kehidupan kolektif dan masyarakat inilah yang menjadi salah satu pihak yang berusaha untuk melakukan upaya perlindungan untuk mengatasi permasalahan sosial anak pemulung di area pemukiman Tempat Pembuangan akhir TPA Puuwatu dibidang ekonomi dan pendidikan melalui mahasiswa dan masyarakat yang biasanya turun langsung mengajar anak-anak dan memberikan bantuan-bantuan seperti makanan, sembako dan pakaian layak pakai. Selanjutnya pihak Pemerintah adalah organisasi yang memiliki kewenangan untuk membuat dan menerapkan hukum serta undang-undang di wilayah tertentu, yang juga berusaha untuk melakukan upaya perlindungan untuk mengatasi permasalahan sosial anak dibidang pendidikan, Ekonomi dan Kesehatan melalui pihak sekolah dan posyandu terkadang juga mereka di memberikan sembako. Selanjutnya pihak Swasta juga berusaha untuk melakukan upaya perlindungan untuk mengatasi permasalahan sosial anak anak dibidang ekonomi seperti memberikan bantuan-bantuan berupa sembako dan pakaian layak pakai.

\section{DAFTAR PUSTAKA}

Adi, fahrudin 2012. Pengantar kesejahteraan sosial. Bandung. Pt refika aditama. 
Asdar, marwah., 2013. Peran pekerja sosial dalam menangani masalah sosial anak (studi di panti sosial asuhan anak dan remaja (psar) kota kendari). skripsi fakultas ilmu sosial dan ilmu politik. Universitas haluoleo. Kendari.

Damanhuri, Enri, 1995, Teknik Penanganan Dan Pembuangan Akhir. Bandung Teknik Lingkungan ITB.

Damanhuri, Enri. 2005. "Longsornya TPA Leuwigajah Melengkapi Citra Buruk TPA di Indonesia”. Departemen Teknik Lingkungan FTSP ITB.

Didang kadir., 2016. Formasi social pemulung. Oase pustaka, surakarta.

Edi suharto. (2013). Kebijakan sosial sebagai kebijakan publik. Bandung: alfabeta.

Gustave Kossi Agbeviade, Djoke; Djadou, Ayawo; Amele d'Almeida; and Rachidatau Ruffino. (2010). Profiling Child Poverty in Four WAEMU Countries: A. Comparative Analysis Based on the Multidimensional Poverty Approach. Canada: Springer.

Koenan, r.a., 2005. Susunan pidana dalam negara sosialis indonesia, bandung : sumur.

Maidin Gultom. 2008. Perlindungan Hukum Terhadap Anak Dalam Sistem Peradilan Anak Di Indonesia. Bandung: Refika Aditama.

Midgley, James, 1997. Social Welfare in Global Context, London : Sage Publication.

Philipus M. Hadjon. 1987. Perlindungan Hukum Bagi Rakyat Indonesia. Surabaya Bina Ilmu.

Rukminto isbandi 2013 kesejahteraan sosial (pekerjaan sosial, pembangunan sosial, dan kajian pembangunan) jakarta:pt.rajagafindo.

Suharto, Edi (2005b), Analisis Kebijakan Publik: Panduan Praktis Mengkaji Masalah Dan Kebijakan Sosial, Bandung: Alfabeta.

Suharto, Edi. 2004. Pendekatan Pekerjaan Sosial Dalam Pemberdayaan Masyarakat Miskin Konsep, Indikator, dan Strategi.

Suharto. 2009. Membangun masyarakat memberdayakan rakyat. Pt refikaaditama: bandung. 
Twikromo, y. Argo., 1999. Pemulung jalanan. Yogyakarta. Yogyakarta : media presindo.

UNICEF. (2016). The State of The World Children's 2016 A Fair Chance For Every Child.

Wahyudi, N.T. 2017. Hubungan Karakteristik Petugas Kebersihan Dengan Pengelolaan Sampah Di Puskesmas Kota Banjarbaru. Jurnal Publikasi Kesehatan Masyarakat Indonesia, Vol. 4 No. 2,hlm. 62-66.

Sumber undang-undang:

Undang-undang nomor 11 tahun 2009 tentang kesejahteraan sosial pasal 1 ayat 1 UU RI Nomor 23 tahun 2002 tentang perlidungan anak

Sumber kantor kelurahan puuwatu:

Sumber Data : Kantor Kelurahan Puuwatu 